\title{
Comportamento de nidificação de Melipona scutellaris (Latreille, 1811)
}

\author{
Nesting behavior of Melipona scutellaris (Latreille, 1811) \\ Comportamiento de anidación de Melipona scutellaris (Latreille, 1811)
}

Recebido: 20/05/2021 | Revisado: 29/05/2021 | Aceito: 31/05/2021 | Publicado: 13/06/2021

\author{
Flávia Janaína de Araújo Silva \\ ORCID: https://orcid.org/0000-0003-2470-2616 \\ Universidade Federal da Paraíba, Brasil \\ E-mail: flaviasume@gmail.com \\ Italo de Souza Aquino \\ ORCID: https://orcid.org/0000-0002-7948-8760 \\ Universidade Federal da Paraíba, Brasil \\ E-mail: italo.aquino@terra.com.br \\ Alex da Silva Barbosa \\ ORCID: https://orcid.org/0000-0002-7343-6134 \\ Universidade Federal da Paraíba, Brasil \\ E-mail: aldasibarbosa@cchsa.ufpb.br \\ Péricles de Farias Borges \\ ORCID: https://orcid.org/0000-0003-3585-1342 \\ Universidade Federal da Paraíba, Brasil \\ E-mail: pericles@cca.ufpb.br
}

\begin{abstract}
Resumo
A ambiência é um dos fatores relevantes na criação racional de abelhas. A abelha uruçu (Melipona scutellaris) é uma espécie nativa do Brasil, conhecida por sua grande produção de mel em relação aos demais meliponíneos e fácil manejo. A enxameação, porém, pode desestabilizar a produção de mel. O objetivo dessa pesquisa foi estudar o comportamento de nidificação da abelha M. scutellaris em colmeias octogonais expostas aos fatores abióticos do ambiente. O experimento foi desenvolvido em dois municípios (Lagoa Seca e Areia) localizados na microrregião do brejo paraibano. Utilizou-se 20 colmeias octogonais, com 8 orifícios cada, representando os pontos cardeais (N, S, L, O) e colaterais (NE, SE, SO e NO). Avaliou-se a influência do horário de nidificação, evolução do fechamento dos orifícios, efeito da direção e velocidade do vento, e influência da temperatura e umidade relativa do ar na abertura e fechamento dos orifícios de nidificação. Conclui-se que 1. A atividade de fechamento dos orifícios da colmeia octogonal com $M$. scutellaris acontece com mais frequência no período da tarde (das 12 às 16 horas); 2. Em Lagoa Seca-PB, as abelhas M. scutellaris apresentam preferência de nidificação na orientação colateral NE, evitando a orientação O; 3. Em Areia$\mathrm{PB}$, as abelhas $M$. scutellaris preferem a orientação cardeal N como ponto de nidificação e evitam a orientação SE; 4 . $\mathrm{O}$ aumento da temperatura e da umidade relativa do ar aumentam a abertura dos orifícios em colmeias octogonais ocupadas por M. scutellaris; e 5 . O aumento na incidência e velocidade do vento reduzem a possibilidade da existência de orifícios abertos em colmeias octogonais povoadas com M. scutellaris.
\end{abstract}

Palavras-chave: Melipona scutellaris; Orientação magnética; Nidificação; Colmeias octogonais.

\begin{abstract}
Ambience is one of the relevant factors in the rational breeding of bees. The uruçu bee (Melipona scutellaris) is a species native to Brazil, known for its large production of honey in relation to other meliponines and easy handling. Swarming, however, can destabilize honey production. The objective of this research was to study the nesting behavior of the $M$. scutellaris bee in octagonal hives exposed to abiotic factors in the environment. The experiment was carried out in two municipalities (Lagoa Seca and Areia) located in the micro-region of the Paraíba swamp. Twenty octagonal beehives were used, with 8 holes each, representing the cardinal (N, S, L, O) and collateral (NE, SE, SO and NO) points. The influence of the nesting time, evolution of the closing of the holes, effect of the direction and speed of the wind, and influence of the temperature and relative humidity of the air in the opening and closing of the nesting holes were evaluated. It is concluded that 1 . The activity of closing the holes of the octagonal hive with M. scutellaris happens more frequently in the afternoon (from $12 \mathrm{pm}$ to $4 \mathrm{pm}$ ); 2. In Lagoa Seca-PB, the M. scutellaris bees have a preference for nesting in the NE collateral orientation, avoiding the $\mathrm{O}$ orientation; 3. In Areia-PB, the M. scutellaris bees prefer the cardinal orientation $\mathrm{N}$ as a nesting point and avoid the SE orientation; 4. The increase in temperature and relative humidity increases the opening of the orifices in octagonal hives occupied by M. scutellaris; and 5 . The increase in wind incidence and speed reduces the possibility of opening holes in octagonal hives populated with M. scutellaris.
\end{abstract}

Keywords: Melipona scutellaris; Orientation; Nesting; Octagonal boxes. 


\begin{abstract}
Resumen
El ambiente es uno de los factores relevantes en la cría racional de abejas. La abeja uruçu (Melipona scutellaris) es una especie originaria de Brasil, conocida por su gran producción de miel en relación con otras meliponinas y su fácil manejo. Sin embargo, el enjambre puede desestabilizar la producción de miel. El objetivo de esta investigación fue estudiar el comportamiento de nidificación de la abeja M. scutellaris en colmenas octogonales expuestas a factores abióticos del medio. El experimento se llevó a cabo en dos municipios (Lagoa Seca y Areia) ubicados en la microrregión del pantano de Paraíba. Se utilizaron veinte colmenas octogonales, con 8 agujeros cada una, que representan los puntos cardinales (N, S, L, O) y colaterales (NE, SE, SO y NO). Se evaluó la influencia del tiempo de anidación, evolución del cierre de los orificios, efecto de la dirección y velocidad del viento, e influencia de la temperatura y humedad relativa del aire en la apertura y cierre de los huecos de anidación. Se concluye que 1. La actividad de cerrar los orificios octogonales de la colmena con M. scutellaris ocurre con mayor frecuencia por la tarde (de 12 a 16 horas); 2. En Lagoa Seca-PB, las abejas $M$. scutellaris tienen preferencia por anidar en la orientación colateral NE, evitando la orientación $\mathrm{O}$; 3. En Areia-PB, las abejas M. scutellaris prefieren la orientación cardinal N como punto de anidación y evitan la orientación SE; 4. El aumento de temperatura y humedad relativa aumenta la apertura de los orificios en las colmenas octogonales ocupadas por M. scutellaris; y 5 . El aumento de la velocidad y la incidencia del viento reduce la posibilidad de que se abran huecos en las colmenas octogonales pobladas por M. scutellaris.
\end{abstract}

Palabras-clave: Melipona scutellaris; Orientación magnética; Anidación; Colmenas octogonales.

\title{
1. Introdução
}

A criação de meliponíneos inicialmente desenvolvida pelos índios, aqui no Brasil, vem sendo praticada nos dias atuais, similarmente, por pequenos e médios produtores, principalmente por aqueles que usam mão de obra familiar nas atividades agropecuárias visando uma atividade econômica complementar (Coletto-Silva, 2005). Diferentemente da apicultura, essa atividade não demanda o uso de indumentária devido ao comportamento dócil da maioria das abelhas indígenas. Também, não há necessidade de que seja respeitada uma distância entre o meliponário e edificações residenciais podendo, inclusive, serem criadas em alpendres, jardins e apartamentos.

A abelha uruçu é uma palavra que vem do tupi "eiru'su", que nessa língua indígena significa "abelha grande". As colônias de Melipona scutellaris são compostas de 300 a 600 indivíduos aproximadamente (Lindauer \& Kerr 1960; Nogueira Neto, 1970; Kerr et al., 1996). Segundo Aquino (2006), a M. scutellaris pesa, em média, 0,07600g, mede 10,4mm e sua ocorrência é comum em todas as microrregiões da Paraíba, onde nidificam espécies vegetais como imburana, umbuzeiro e faveleira. Essas abelhas habitam todas as regiões tropicais do planeta com cerca de 300 espécies e aproximadamente 50 espécies da tribo Meliponini ocorrem exclusivamente nas Américas, inclusive na Caatinga, onde essas abelhas possuem hábitos de nidificação distintos (Pirani \& Cortopassi-Laurino, 1993).

Atualmente, a Caatinga tem sido alvo de dois grandes impactos da ação do homem: o corte de árvores para utilização como lenha e o uso do solo para pecuária. Algumas regiões da Caatinga já possuem sinais de desertificação (Martins et al., 2004). Por conta desse processo antrópico, o número de colônias é drasticamente afetado (Silva, 2015). Kerr et al. (1996), enfatiza a importância das abelhas ao caracterizá-las como parte integrante do ecossistema da região em que vivem. Sua principal função na natureza é ser o vetor biótico que realiza a polinização cruzada de forma efetiva nas plantas. Sem este serviço, a maioria das plantas com flores teriam seu sucesso reprodutivo afetado (Kerr, 1997).

O mel e a própolis de abelhas nativas, especialmente de M. scutellaris, são reconhecidos popularmente como "medicinal", mas muitos utilizam esses produtos como um complemento alimentar. Infelizmente, a escassez de ninhos de abelhas nativas, a falta de divulgação da existência dos meliponários e a desinformação do produtor rural com relação ao manejo adequado de meliponíneos (principalmente quanto à habilidade de multiplicação e beneficiamento do mel) são os principais gargalos da cadeia produtiva, sendo necessário, também, estudos para elucidar os hábitos comportamentais em relação ao meio em que vivem.

De acordo com Lucano (2006), insetos e outros animais possuem um sistema magneto-receptor constituído por materiais biomineralizados localizados em certas regiões de seus corpos. Esse sistema permite que muitos seres vivos sejam sensíveis ao campo geomagnético, orientando-se através dele em suas migrações. Estudos geológicos mostram que o processo de 
biomineralização iniciou-se em muitas espécies no período pré-cambriano (Lowenstam, 1981). Lowenstam, (1962) foi o primeiro a observar a magnetita $(\mathrm{Fe} 3 \mathrm{O} 4)$ recobrindo os dentes de chitons. A magnetita biogênica foi encontrada, também, na bactéria magnetotáctica e, subsequentemente, em abelhas, tartarugas marinhas, pássaros, peixes e outros animais que possivelmente se orientam através do campo da terra (Frankel et al., 1979).

Há muito tempo, estudos vêm sendo desenvolvidos com a abelha Apis mellifera mostrando a correlação entre seu comportamento e o campo geomagnético. Nas Apis, por exemplo, foram observadas partículas de magnetita na região abdominal (HSU, 1994). Esse senso de orientação dos animais também pode ser influenciado em função de melhorias na ambiência da habitação. A entrada dos ninhos diferencia-se externamente entre as duas tribos. Enquanto na maioria dos Trigonini a entrada apresenta-se na extremidade de um tubo de cerume de tamanhos variados, na tribo Meliponini a entrada da colmeia é caracterizada por um orifício pequeno localizado no centro de uma estrutura raiada, feita a partir de terra ou argila e resinas vegetais (Aquino, 2006).

Silva e Paz (2012) e Coletto-Silva (2005) afirmam que a criação de melíponas ainda é muito carente no Brasil, necessitando de práticas tecnológicas que aprimorem sistema de manejo das abelhas e o processo de extração dos produtos, tornando-os mais valorativos. Em termos de manejo, ainda é precário informações sobre o comportamento dessas abelhas entre os meliponicultores.

O objetivo dessa pesquisa foi estudar o comportamento de nidificação da abelha Melipona scutellaris em colmeias octogonais expostas aos fatores abióticos do ambiente. O experimento foi desenvolvido em dois municípios, Lagoa Seca e Areia, ambos localizados na microrregião do brejo paraibano.

\section{Material e Métodos}

O experimento foi conduzido e no período de 13 de setembro a 18 de novembro de 2015. A primeira parte da pesquisa foi desenvolvida na Estação Experimental da Empresa Estadual de Pesquisa Agropecuária da Paraíba (EMEPA) [07 10' 15" S, 35 51' 13” W.], polo de Lagoa Seca-PB, Sitio Imbaúba, Mesorregião do agreste Paraibano. A EMEPA, localizada a uma altitude de $634 \mathrm{~m}$, possui verões secos e inverno com temperaturas que caem com facilidade (As). A pluviosidade média em Lagoa Seca é de $940 \mathrm{~mm}$, com maior incidência de chuva no período entre os meses de março e agosto; a umidade relativa do ar média (UR) é em torno de $60 \%$ e a temperatura média anual é de $25^{\circ} \mathrm{C}$ (Fideles Filho et al., 2002).

A segunda parte do experimento foi desenvolvida no Centro de Ciências Agrárias (CCA), da Universidade Federal da Paraíba (UFPB), município de Areia-PB (6 $6^{\circ} 58^{\prime} 20.3^{\prime \prime S}, 35^{\circ}$ 42' 59.4"W), mais precisamente na reserva ecológica Mata do Pau Ferro, localizada entre os Departamentos de Fitotecnia e Botânica a uma altitude de $618 \mathrm{~m}$. O clima de Areia-PB é tropical úmido, com estação chuvosa no período de outono-inverno, apresentando temperatura média de $23^{\circ} \mathrm{C}$, UR média de $80 \%$ e uma precipitação média anual de $1.400 \mathrm{~mm}$ (CCA, 2016).

Foram utilizadas 20 colmeias octogonais (Aquino, 2019) com perfurações de $5 \mathrm{~mm}$ de diâmetro em cada uma das oito faces representando os pontos cardeais (Norte, Sul, Leste, Oeste) e colaterais (nordeste, sudeste, sudoeste, noroeste). Nessas colmeias, foram acomodados ninhos de Melipona scutellaris (Figura 1); dez colmeias em cada município (Lagoa Seca e Areia). Originalmente, 20 colônias de M. scutellaris, acomodadas em colmeias padrão, foram levadas até as áreas experimentais, com quatro dias de antecedência, antes de serem transferidas para as colmeias octogonais. Após esse período, as famílias foram transferidas para as colmeias octogonais, posicionadas em suportes de $1,20 \mathrm{~m}$ de altura, separados a $2 \mathrm{~m}$ de distância uma da outra. Utilizou-se o aplicativo Bússola Smart Compass ${ }^{\circledR}$ para smartphone MOTO®G, de modo que as colmeias fossem posicionadas com os orifícios de nidificação alinhados nas direções dos pontos cardeais e colaterais. 
Figura 1. Transferência de uma colônia de Melipona scutellaris em colmeia padrão (A) para uma colmeia octogonal (B).

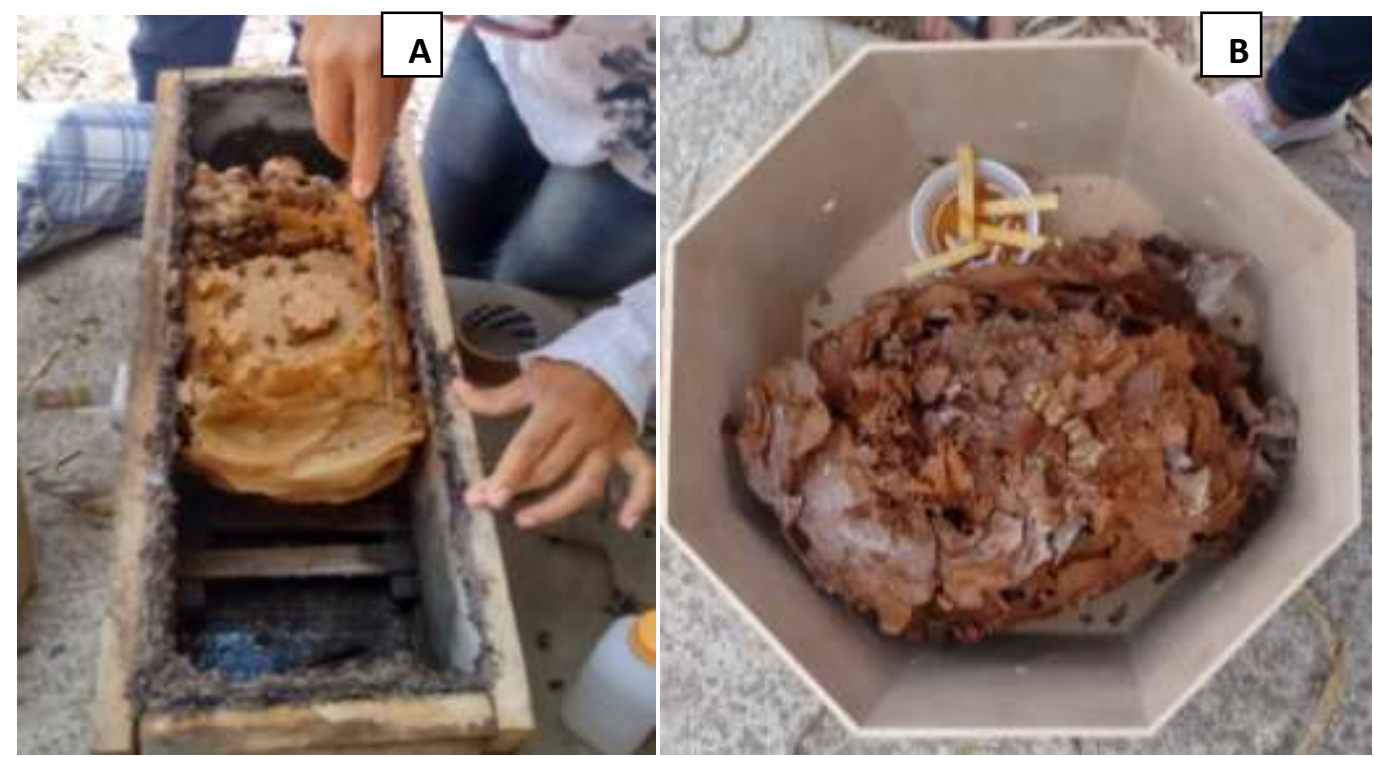

Fonte: Silva et al. (2021)

Durante o processo de transferência evitou-se ao máximo que potes de alimento (de pólen principalmente) fossem violados para que não atraíssem inimigos naturais como forídeos e formigas. Para conter possíveis infestações de insetos invasores, foram instaladas armadilhas; para forídeos, foram confeccionadas armadilhas em recipientes plásticos contendo vinagre; para as formigas, foram colocadas esponjas embebidas com óleo queimado nos suportes das colmeias octogonais. Devido ao estresse causado nas abelhas pela transferência e da impossibilidade de deixar potes de alimento violados nas caixas octogonais, fez-se necessário a suplementação diária $(50 \mathrm{ml})$ das abelhas com alimento à base de água e açúcar (1:1).

Os dados abióticos de temperatura média, velocidade e direção do vento e UR foram coletados através da estação meteorológica da EMEPA (Lagoa Seca) e de uma mini estação meteorológica Oregon Scientific ${ }^{\circledR}$, WMR928NX (Areia). Os 20 ninhos foram transferidos para as colmeias octogonais em períodos de tempo distintos (em até uma semana), totalizando cinco etapas de observação. No primeiro momento, foram dispostas 2 colmeias na EMEPA por um período de 37 horas. Após esse período as colmeias eram retiradas e substituídas por outras colmeias com novas famílias, de acordo com a disponibilidade de material e do tempo que as abelhas levavam para fechar os orifícios. O processo de instalação das colmeias foi semelhante nos dois municípios. Todos as informações foram incluídas em um banco de dados do programa Excel ${ }^{\circledR}$, versão 2007 e submetidos à análise estatística. Os dados de probabilidade para se encontrar orifícios abertos em colmeias de abelhas M. scutellaris foram submetidos ao teste de Qui-quadrado $(\mathrm{p} \leq 0,05)$ para se verificar os efeitos dos fatores em estudo. As médias dos fatores qualitativos foram comparadas pelo teste de Tukey $(\mathrm{p} \leq 0,05)$ e dos fatores quantitativos (temperatura, UR e velocidade do vento) ajustados ao modelo logístico binomial.

\section{Resultados e Discussão}

Os experimentos foram realizados em um período de 22, totalizando 2.280 observações sobre o fechamento dos orifícios de nidificação nas colmeias octogonais bem como e sobre dados abióticos do ambiente. Foram analisadas as interações entre os horários das observações, local onde foi desenvolvido o experimento e orientação dos alvados e, ainda, a influência da direção e velocidade do vento, temperatura e UR sobre a preferência da orientação para nidificação de $M$. scutellaris em colmeias octogonais nos municípios de Lagoa Seca e Areia, PB. A única interação estatisticamente significativa ocorreu entre orientação 
(OR) e os locais onde os experimentos foram desenvolvidos (LL) [Tabela 1]. O horário das observações (H) interferiu apenas de forma isolada nos resultados, ou seja, não interferiu ou foi afetado pelos outros dois fatores.

Tabela 1. Análise de Qui-quadrado da probabilidade de encontrar orifícios abertos em colmeias octogonais contendo abelhas da espécie Melipona scutellaris em relação à orientação do orifício, horário de avaliação e localização do experimento (Lagoa Seca e Areia, PB).

\begin{tabular}{lcrrr}
\hline \multicolumn{1}{c}{ Fonte de variação } & GL & $\boldsymbol{\chi 2}$ & P \\
\hline Orientação (OR) & 7 & 118,4248 & $<0,0001$ \\
Horário (H) & 2 & 14,6388 & 0,0007 \\
Local (LL) & 1 & 0,0074 & 0,9312 \\
OR x H & 14 & 3,3211 & 0,9984 \\
OR x LL & 7 & 69,9534 & $<0,0001$ \\
H x LL & 2 & 0,5800 & 0,7483 \\
OR x H x LL & 14 & 3,0216 & 0,9990 \\
\hline
\end{tabular}

Fonte: Silva et al. (2021)

Observa-se (Figura 2) que às 8h:00min, a probabilidade de encontrar orifícios abertos nas colmeias octogonais é maior (71\%) que nos demais horários. Às 12h:00min a probabilidade de encontrar orifícios abertos não diferiu estatisticamente das outras duas observações (68\%), porém às 16h:00min, essa probabilidade diminuiu (60\%).

Figura 2. Probabilidade de encontrar orifícios abertos em colmeias octogonais contendo abelhas da espécie Melipona scutellaris em relação ao horário de avaliação.

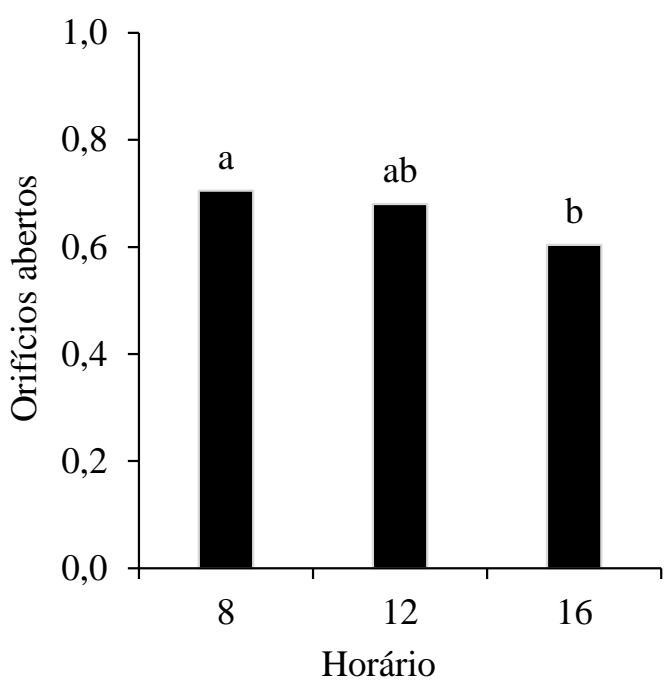

Médias seguidas pela mesma letra não diferem entre si pelo teste de Tukey $(\mathrm{p} \leq 0,05)$; Fonte: Silva et al. (2021).

Ao meio dia, a quantidade de orifícios abertos praticamente não difere dos demais horários de observação. Porém, em torno das 16h:00min a atividade de fechamento dos orifícios aumenta, diminuindo a probabilidade de encontrar orifícios abertos nas caixas octogonais nesse horário. Ou seja, a atividade de fechamento dos orifícios pela espécie M. scutellaris ocorre com maior intensidade no período da tarde. Esses resultados corroboram com Mesquita et al. (2002), onde observaram que abelhas F. varia aumentam a frequência de entrada e saída do ninho nos horários em que as temperaturas estavam mais elevadas, por volta das 12h:00min e 16h:00min. Semelhantemente, esses dados se assemelham aos encontrados por Lacerda et al. (2017) em seus estudos com Scaptotrigona postica em colmeias octogonais na zona da mata pernambucana. 
Percebe-se (Figura 3) que no primeiro dia de observação do experimento a probabilidade de encontrar orifícios abertos nas caixas octogonais é muito alta (99\%). Porém, essa probabilidade diminuiu nos dois dias subsequentes (81 e 57\%), estabilizando-se a partir do quarto (42\%) até o sexto dia (47\%) de observação. No sétimo dia a probabilidade de encontrar orifícios abertos é ainda menor (23\%).

Figura 3. Probabilidade de encontrar orifícios abertos em colmeias octogonais contendo abelhas da espécie Melipona scutellaris em relação aos dias após a instalação.

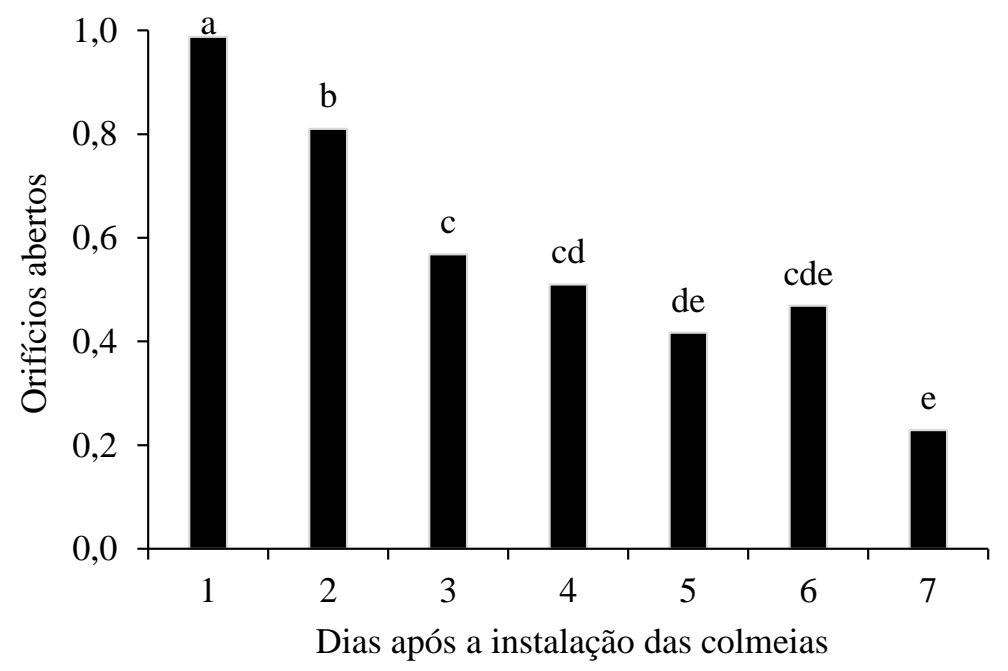

Médias seguidas pela mesma letra não diferem entre si pelo teste de Tukey $(\mathrm{p} \leq 0,05)$. Fonte: Silva et al. (2021).

Logo após a instalação do experimento as abelhas demonstraram desorientação, entrando e saindo por todos os orifícios das colmeias octogonais. Porém, oito horas após a instalação dessas colmeias em campo, já foi possível notar a presença de um grande número de abelhas em seu interior e uma abelha vigia em cada um dos orifícios de entrada. Ainda, verificou-se que, em alguns orifícios, já havia o depósito de pequenas partículas de cerume, demonstrando o início da rejeição dos orifícios em diferentes orientações magnéticas. A velocidade do fechamento dos orifícios de nidificação dependeu dos fatores abióticos de cada área.

\section{Efeito da direção do vento na probabilidade de encontrar orifícios abertos em colmeias octogonais}

É possível observar (Figura 4) que a maior probabilidade de encontrar orifícios abertos na nas caixas octogonais instaladas no município de Lagoa Seca foi na orientação NE (85\%), seguidos de L (78\%), N (73\%). A probabilidade de encontrar orifícios abertos diminuiu gradativamente nos pontos S (58\%), SE (57\%), SO (56\%). As orientações menos preferidas foram O (40\%) e NO $(43 \%)$. 
Figura 4. Probabilidade de encontrar orifícios abertos em colmeias octogonais contendo abelhas da espécie Melipona scutellaris em relação à orientação do orifício no município de Lagoa Seca-PB.

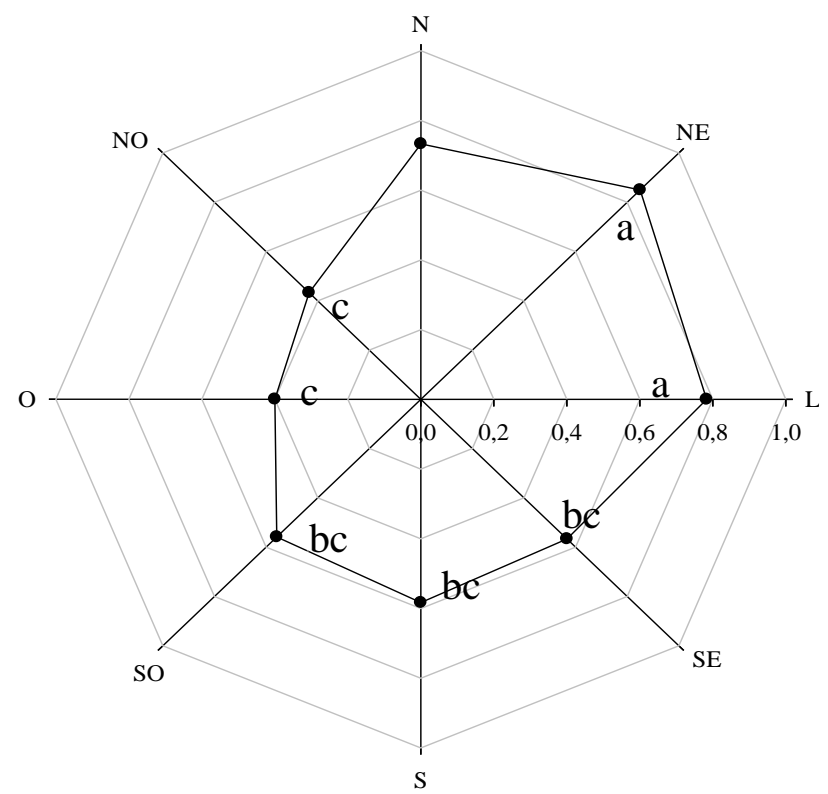

Fonte: Silva et al. (2021).

Verificou-se que há uma grande probabilidade de ocorrer efeito da direção do vento sobre o fechamento dos orifícios (Figura 5) no ponto cardeal O, seguido de SO e NO. Não foram observados ventos do N, NE, L, SE e S. Logo, tomando a Figura 3 como referência, pode-se afirmar que o vento é um fator abiótico que influencia diretamente na atividade de fechamento e escolha dos orifícios das caixas octogonais no município de Lagoa Seca, já que a probabilidade de encontrar orifícios abertos na orientação NE foi superior as demais.

Figura 5. Efeito da direção do vento na probabilidade de encontrar orifícios abertos em colmeias octogonais contendo abelhas Melipona scutellaris no município de Lagoa Seca -PB.

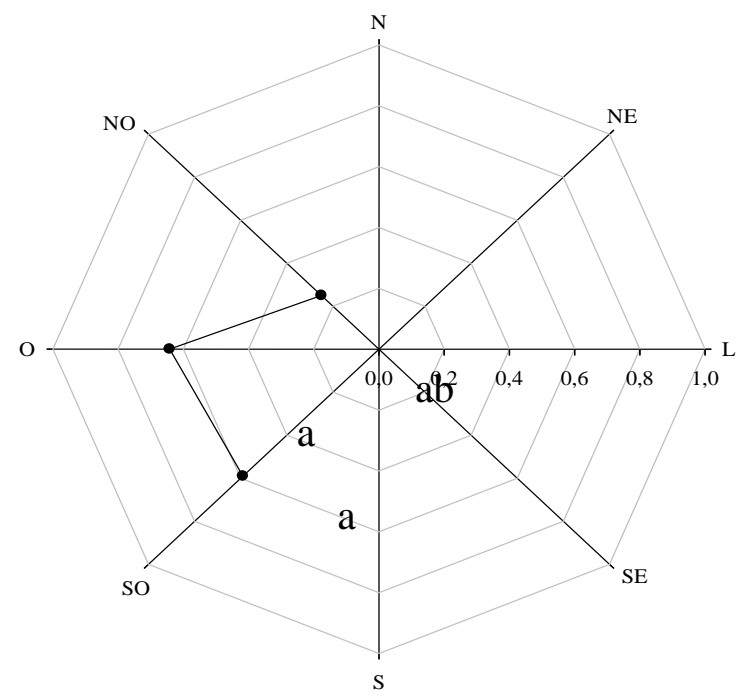

Médias seguidas pela mesma letra não diferem entre si pelo teste de Tukey ( $\mathrm{p} \leq 0,05)$. Fonte: Silva et al. (2021). 
Observa-se (Figura 6) que existe uma alta probabilidade de abelhas da espécie $M$. scutellaris iniciarem o fechamento dos orifícios das caixas octogonais localizados no ponto colateral SE (38\%) e ponto cardeal S (50\%). A probabilidade de encontrar orifícios fechados diminui gradativamente nos pontos SO (68\%), L (70\%) e O (67\%), e continua caindo nos pontos NO $(79 \%)$ e NE (89\%). A maior probabilidade de encontrar orifícios abertos foi observada no ponto cardeal N (98\%).

Figura 6. Probabilidade de encontrar orifícios abertos em colmeias octogonais contendo abelhas Melipona scutellaris em relação à orientação do orifício no município de Areia-PB.

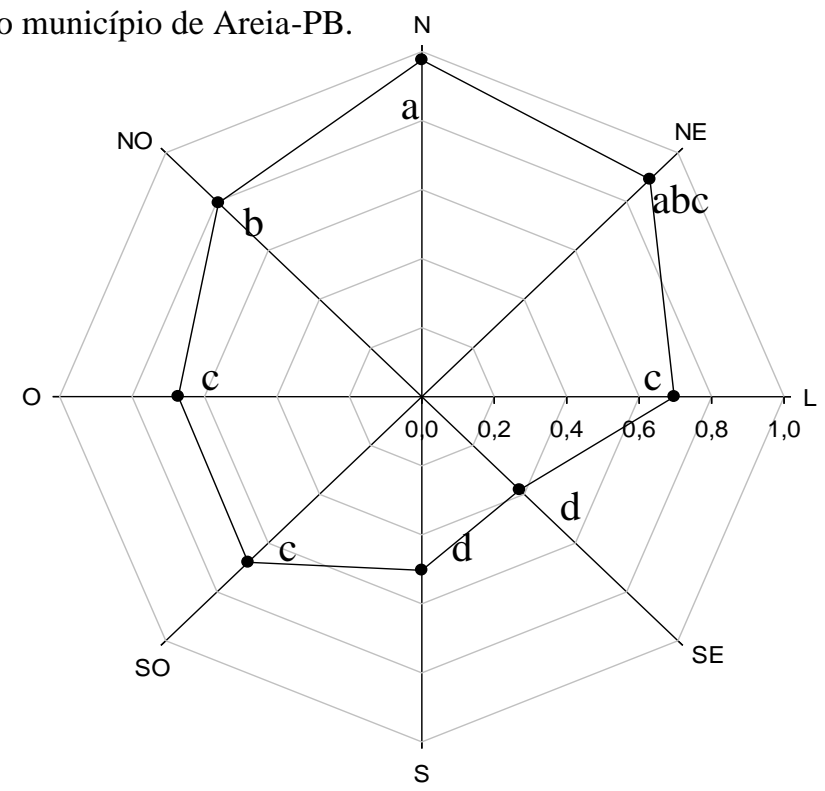

Médias seguidas pela mesma letra não diferem entre si pelo teste de Tukey $(\mathrm{p} \leq 0,05)$. Fonte: Silva et al. (2021).

Observa-se (Figura 7) que a probabilidade de encontrar orifícios abertos de acordo com a influência do vento foi menor nos pontos S, SO e NO. Essa probabilidade aumentou gradativamente nos pontos O, SE e L. A maior probabilidade de encontrar orifícios abertos foi observada na orientação N e NE. Nesses pontos, não foram observados a ocorrência ventos e, desta forma, observou-se maior probabilidade de encontrar orifícios abertos em relação aos demais orifícios. 
Figura 7. Efeito da direção do vento na probabilidade de encontrar orifícios abertos em colmeias octogonais contendo abelhas Melipona scutellaris no município de Areia-PB.

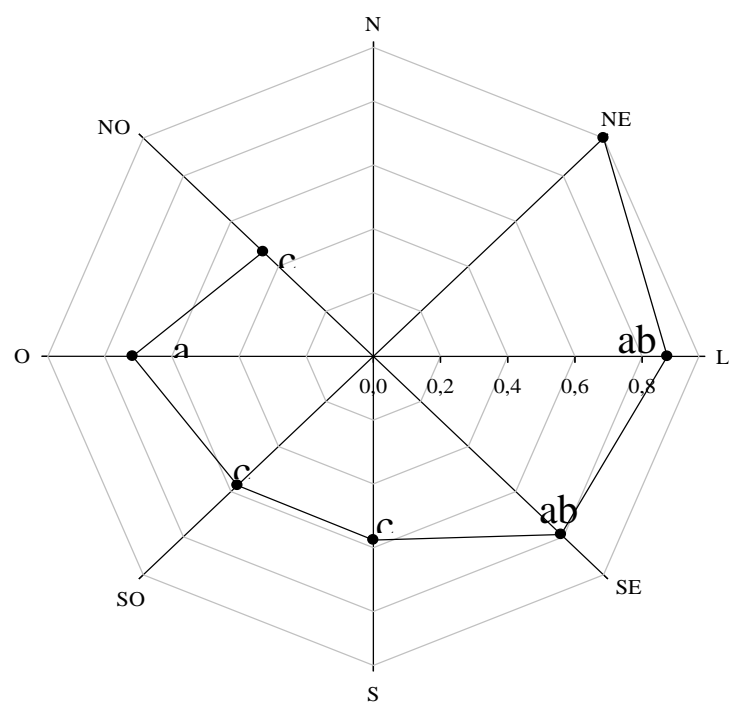

Médias seguidas pela mesma letra não diferem entre si pelo teste de Tukey $(\mathrm{p} \leq 0,05)$. Fonte: Silva et al. (2021).

Fazendo-se uma análise das Figuras 4, 5, 6 e 7 é possível afirmar que o comportamento das abelhas tem relação direta com a rejeição dos lados das colmeias octogonais que recebiam maior índice de rajadas de vento. Certamente essas abelhas assumiram esse comportamento com a finalidade de se favorecem nos aspectos de voo e proteção das crias. À medida que a incidência de vento aumentou em uma orientação, aumentou, também, a probabilidade do fechamento dos orifícios desse ponto. Srinivasan et al. (1997) observaram que, nas abelhas, a percepção do vento ocorre por meio de pelos que estão sobre a cabeça e olhos. Segundo Ferreira (2009) as abelhas utilizam suas asas com mais precisão ao estarem contra a corrente de vento. Dessa forma, a direção vento pode ser considerada uma limitação que explique o a baixa probabilidade de encontrar orifícios abertos nos pontos onde foram observadas maiores incidências de vento, haja vista que este fator abiótico dificulta que as abelhas mantenham a estabilidade durante a saída (decolagem) e chegada (pouso) na colmeia, gastando muita energia para desempenhar essas atividades. A direção do vento, por exemplo, influencia a atividade de voo das forrageiras de $P$. remota conforme relato de Hilário et al. (2007). Esse autor verificou que menores atividades de voo aconteceram quando o vento soprava em sentido contrário ao deslocamento da forrageira para fora da colônia; ou seja, provavelmente as forrageiras escolham voar a favor do vento.

Bizotto e Santos (2015) observaram em polinização em macieiras que as abelhas melíferas batedoras calculam gastos de energia antes de partirem para a coleta de recursos e, assim, optam por deslocamentos mais curtos a fim de economizar energia durante trajeto. Além dos aspectos relacionados ao voo, esses pesquisadores alertam que esse comportamento pode levar a perdas elevadas de produção já que a polinização estaria sendo afetada. Observou-se que no ato da transferência dos ninhos para as colmeias octogonais as lamelas eram inevitavelmente destruídas para que se pudesse fazer a retirada dos discos de cria. Com o estresse dessa transferência, verificou-se que as abelhas dedicaram esforços para a reconstrução do invólucro das crias concomitantemente com o fechamento dos orifícios de nidificação indesejados.

Vaz (2015) constatou em experimento realizado com F. dispar em colmeias octogonais, instaladas em Jardim do Seridó$\mathrm{RN}$, que essa espécie possuiu preferência de nidificação pelos orifícios orientados no ponto cardeal L e menor preferência para o ponto cardeal S. Esses dados podem ser comparados com os dados deste trabalho, pois as abelhas da espécie M. scutellaris também optaram por deixar os orifícios abertos com maior frequência no primeiro quadrante dos gráficos de radar ( $\mathrm{N}$, NE e L). 
Nogueira Neto (1970) assevera que a pouca incidência de luminosidade pode atrasar o início do voo das abelhas e que quanto mais cedo elas entram em contato com os raios solares, mais cedo podem se orientar para iniciar os trabalhos externos. Isso explicaria o fato da maioria dos ninhos optarem pelas orientações voltadas para o alvorecer. A mesma situação não ocorreu no trabalho de Ferreira (2015) que verificou, na região do cariri paraibano, uma nítida preferência da espécie Partamona cupira em construir a entrada de seus ninhos na direção do ponto colateral NO, seguido do ponto SE.

Ferreira (2009) constatou em seu trabalho com abelhas solitárias em ninhos armadilha que o número de nidificações foi reduzido no ponto cardeal L. Considerando que no trabalho desse autor a direção predominante do vento era SE-L, os dados sugerem que a ação do vento foi fator preponderante na escolha da orientação para nidificar. Portanto, ao se montar um meliponário é recomendável que se posicione os alvados numa orientação contrária aos ventos, mas que possua boa incidência de luminosidade.

Nogueira Neto (1970) sugere que as colmeias sejam protegidas contra ventos frios. Para proteger as abelhas desses ventos e facilitar o voo pode- se utilizar cercas vivas no entorno dos meliponários. Martins et al. (2012) afirmam que a importância da intensidade e direção dos ventos para espécies nidificantes em cavidades pré-existentes nunca foi avaliada quantitativamente, e que por isso são necessários ainda estudos microclimáticos mais detalhados para avaliar a ação desse fator natural.

Observa-se (Figura 8) que à medida que a velocidade do vento aumenta, a probabilidade de encontrar orifícios abertos nas caixas octogonais diminuiu.

Figura 8. Efeito da velocidade do vento na probabilidade de encontrar orifícios abertos em colmeias com abelhas Melipona scutellaris.

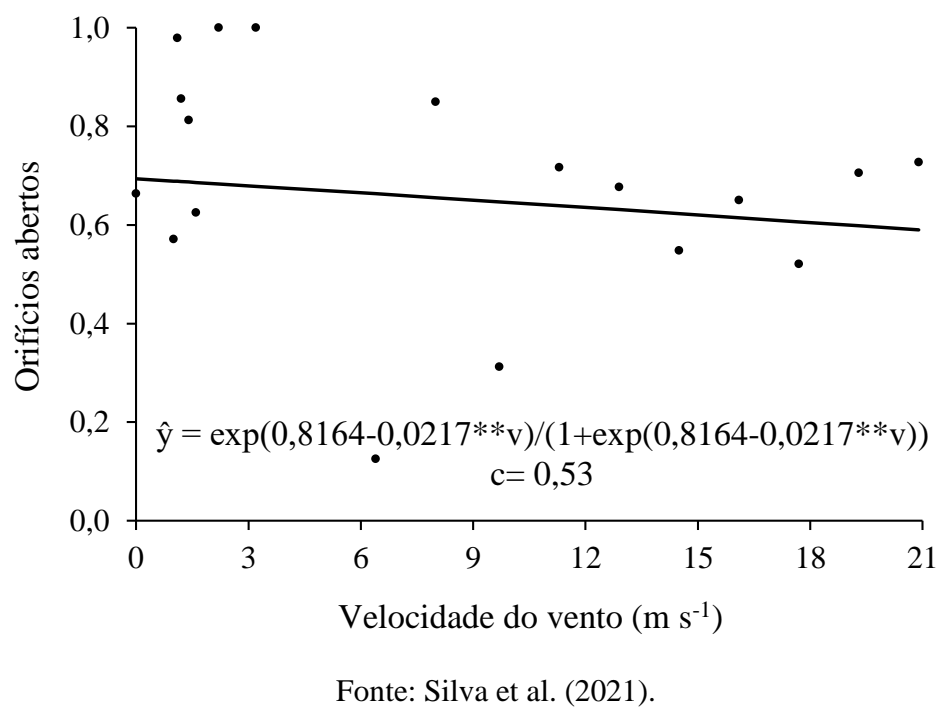

A atividade de voo das abelhas é altamente dependente do ambiente. Fatores climáticos, como: variações de temperatura, de intensidade luminosa, de UR, incidência de vento ou de chuva, modificam, modulam, ou mesmo suprimem a atividade das abelhas (Bugalho, 2009). Aquino (2006), afirma que a maioria das abelhas nativas da Paraíba são encontradas nas regiões do Cariri e Curimataú. Assim, ao se montar o meliponário, o autor recomenda que as colmeias sejam posicionadas no sentido leste-oeste para que o excesso de luminosidade, e que ventos e chuva sejam evitados. 


\section{Influência da temperatura do ar na probabilidade de encontrar orifícios abertos em colmeias octogonais povoadas com} Melipona scutellaris

Fatores externos como a radiação solar, incidência de ventos, chuvas e umidade podem influenciar na temperatura interna dos ninhos. Os seres vivos fazem modificações nos espaços onde habitam principalmente com o intuito de tornar o microclima local agradável. Além de ocasionar a morte das crias, o excesso de incidência solar pode, ainda, causar alteração do cerume, ou até mesmo exterminação da colônia.

Roldão (2011) afirma que a influência de temperatura sobre o desenvolvimento de abelhas A. mellifera em estufas já é bastante conhecida. Em contra partida, informações sobre tais influências sobre as abelhas sem ferrão ainda é escassa na literatura. É sabido, porém, que a temperatura e a incidência de ventos são fatores limitantes no desenvolvimento das abelhas nativas, já que afetam o bem estar no interior do ninho, o desenvolvimento das formas jovens e, consequentemente, a perpetuação da espécie. Assim, é importante que ao se pensar em montar um meliponário, seja dada preferência por um lugar protegido da incidência de ventos fortes e, ao mesmo tempo, que possua boa incidência solar.

Observa-se (Figura 9) que quando a temperatura se encontra em $20,6^{\circ} \mathrm{C}$ a probabilidade de encontrar orifícios abertos nas caixas octogonais foi $69 \%$. A partir de $28^{\circ} \mathrm{C}$ a probabilidade de encontrar orifícios abertos (51\%) é quase igual a probabilidade de encontrar orifícios fechados (49\%). Com o aumento da temperatura para $29,3^{\circ} \mathrm{C}$ a probabilidade encontrar orifícios abertos volta a aumentar de forma significativa (66\%); ou seja, o aumento da temperatura influencia a espécie $M$. scutellaris a desacelerar o processo de fechamento dos orifícios das colmeias octogonais.

Figura 9. Efeito da temperatura do ar na probabilidade de encontrar orifícios abertos em caixas octogonais contendo abelhas Melipona scutellaris.

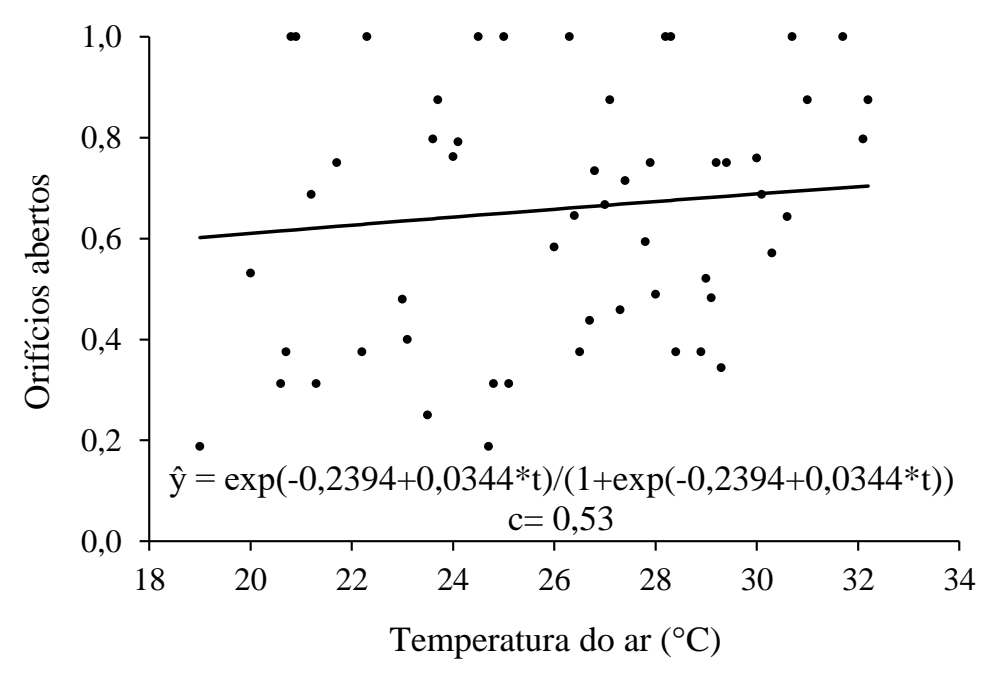

Fonte: Silva et al. (2021).

Observou-se, também, em algumas colmeias instaladas no município de Areia-PB, que nos horários mais quentes do dia as abelhas reabriam alguns orifícios que já haviam sido fechados por elas. É provável que quando a temperatura sobe acima de $29,3^{\circ} \mathrm{C}$ a espécie $M$. scutellaris diminui sua atividade de fechamento dos orifícios das colmeias octogonais com a finalidade de refrigerar o interior da colmeia. Essa conduta protetiva foi observada especialmente em famílias que ainda se encontravam com os discos de cria desprotegidos pelos invólucros no interior das colmeias. Esse comportamento corrobora com dados do trabalho de Vaz (2015), utilizando abelhas F. díspar que apresentam alterações no seu comportamento de nidificação em colmeias octogonais, onde as abelhas abriram e fecharam os orifícios de nidificação de acordo com a elevação da temperatura. 
Silva (2011) observou que a abelha $M$. scutellaris realiza menor atividade de voo sob temperaturas abaixo de $20^{\circ} \mathrm{C}$ ou acima dos $30^{\circ} \mathrm{C}$, e apresenta alto índice de atividade sob temperaturas moderadas $\left(21^{\circ} \mathrm{C} \mathrm{a} 25^{\circ} \mathrm{C}\right)$, registradas no período da manhã. Em seu trabalho com termorregulação em M. scutellaris, Oliveira (2012) verificou que as atividades externas de e M. subnitida ocorrem em sua maioria pela manhã, tanto no período chuvoso quanto no seco.

Nogueira Neto (1970) observou que para se defenderem do calor, as abelhas deixam pequenas aberturas no betume com o intuito de ventilar o ninho e impedir a morte das crias. Isso poderia explicar um fato observado nas caixas octogonais instaladas na cidade de Areia-PB, onde as abelhas demonstraram maior preferência de nidificação para as orientações contrárias ao sol poente.

Efeito da umidade relativa do ar (UR) na probabilidade de encontrar orifícios abertos em colmeias octogonais povoadas com Melipona scutellaris

Nos trópicos úmidos, as alterações presumíveis da temperatura e UR no transcorrer do dia possivelmente colaboram para a performance de voo da abelha Meliponini com distintos tamanhos, coloração etc (Kleinert-Giovannini \& ImperatrizFonseca, 1986).

Observa-se (Figura 10) que quando a UR está com uma saturação de 14,5\%, a probabilidade de encontrar orifícios abertos nas colmeias octogonais é de apenas 38\%. Mas, à medida que a UR aumenta, a probabilidade de encontrar orifícios abertos nas colmeias aumenta, especificamente quando UR chega a 67\%, com a probabilidade de encontrar orifícios abertos em 48\%. Esses dados estão de acordo com Vaz (2015) que verificou no seu trabalho com abelhas nativas que dias com UR mais elevadas as abelhas diminuíam suas atividades em relação a abrir e fechar os orifícios de nidificação em colmeias octogonais.

Figura 10. Efeito da umidade relativa do ar na probabilidade de encontrar orifícios abertos em caixas octogonais contendo abelhas Melipona scutellaris.

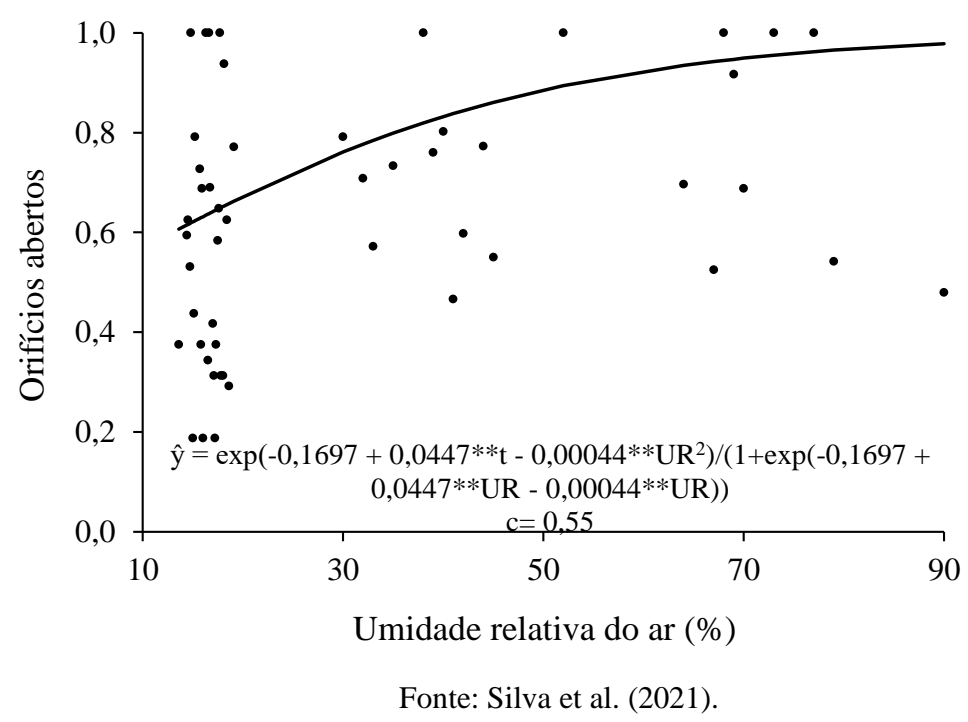

É possível afirmar que quando a UR aumenta muito as abelhas tendem a interromper as atividades de forrageiro e permanecem dentro das caixas. Por isso, a probabilidade se estabiliza quando a UR está igual ou acima de $67 \%$. O mesmo pôde ser visto no trabalho de Bugalho (2009), onde o autor concluiu que o comportamento higiênico das abelhas do gênero Apis é mais eficiente com o aumento da umidade, uma vez que estas diminuem a atividade forrageira em função da incidência de chuvas. 
Silva (2011) constatou que a da atividade de voo de M. scutelaris aumenta rapidamente nos horários do dia com índices de UR mais altas $\left(21^{\circ} \mathrm{C}\right.$ a $\left.25^{\circ} \mathrm{C}\right)$. Cortopassi-Laurino et al. (2007) e Fidalgo e Kleinert (2007) demonstram que o forrageio mais acentuado em busca de pólen tem vinculação com períodos de alta UR. Esses dados não corroboram com os dados obtidos por Hilário et al. (2000) que defendem que espécies de porte menor possuem comportamento de forrageio intenso sob percentuais de UR muito baixos, diminuindo a ação de forrageio à medida que esta aumenta.

Silva (2011) e Alves e Lorenzon (2001) explicam que a prática de forrageio da abelha M. scutellaris, além do impacto da UR pode, do mesmo modo, ter a influência de diversas variáveis como luminosidade, temperatura e disponibilidade de recursos florais. Lima (2015) constatou, em seu trabalho com M. scutellaris, que a produção de geoprópolis mostrou-se um fator inversamente proporcional em relação ao aumento UR. A autora observou que nos meses com fortes chuvas as abelhas diminuíram o seu ritmo de produção de geoprópolis, não vedando por completo o coletor com geoprópolis. Assim, é possível afirmar que à medida que a UR aumenta (igual ou acima que 67\%) as abelhas diminuem a produção de geoprópolis para vedar os orifícios abertos.

A metodologia inovadora utilizada nesta pesquisa é relevante para a meliponicultora. Com a adequação das colmeias, obedecendo a orientação natural de cada espécie, haverá uma otimização de seu potencial produtivo, mais conforto zootécnico e, consequentemente menos enxameação. Com menos "fuga" das abelhas, o meliponicultor poupará mais essências florestais no afã de "caçar" abelhas para sua criação e, desta forma, minimizar, por exemplo, o desmatamento da Caatinga.

\section{Conclusões}

1. A espécie Melipona scutellaris apresenta preferência de nidificação após as primeiras $24 \mathrm{~h}$ depois de acomodadas em colmeias octogonais;

2. A abelha M. scutellaris demonstra atividade de fechamento dos orifícios rejeitados em colmeiasoctogonais no período da tarde (das 12 às 16 horas);

3. Em Lagoa Seca-PB as abelhas M. scutellaris demonstram preferência pela orientação NE como ponto de nidificação;

4. Em Areia-PB as abelhas M. scutellaris demonstram preferência pela orientação $\mathrm{N}$ como ponto de nidificação; e

5. O aumento da temperatura e da umidade relativa do ar incrementa a abertura dos orifícios de em colmeias octogonais contendo M. scutellaris, enquanto que o aumento na incidência e velocidade do vento reduzem a possibilidade da existência de orifícios abertos nessas colmeias.

Espera-se que estudos adicionais sobre o comportamento a nidificação em colmeias octogonais sejam conduzidos com outras espécies de abelhas nativas.

\section{Agradecimentos}

A Empresa Estadual de Pesquisa Agropecuária da Paraíba (EMEPA) e ao Centro de Ciências Agrárias (CCA) da Universidade Federal da Paraíba (UFPB) por disponibilizarem suas áreas experimentais para a realização desta pesquisa.

\section{Referências}

Alves, E. U. \& Lorenzon, M. C. A. (2001). Atividade de voo de Melipona scutellaris (Meliponini) durante as estações seca e chuvosa na região do brejo da Paraíba. Revista Nordestina de Biologia, 15(2), 41-48.

Aquino, I. S. (2006). Abelhas Nativas da Paraíba. Editora Universitária - UFPB. 91 p. 
Aquino, I. S. (2019). Colmeia para abelhas das tribos meliponnini e trigonnini. Depósito de pedido nacional de patente. Depositante: Universidade Federal da Paraíba, INPI BR 1020190117320 A2.

Bizotto, L. A. \& Santos, R. S. S. (2015). Dinâmica de voo e coleta de recursos por Apis mellifera em pomar de macieira. Enciclopédia Biosfera, Centro Científico Conhecer - Goiânia, 11(21), 3499-3506.

Bugalho, V. A. (2009). Influência das precipitações pluviométricas e da atividade forrageira das abelhas africanizadas (Apis mellifera L.) no comportamento higiênico. Dissertação apresentada à Faculdade de Filosofia, Ciências e Letras de Ribeirão Preto/ USP - Departamento de Biologia - Ribeirão Preto, 108 p.

CCA - Centro de Ciências Agrárias (CCA) (2016). Universidade Federal da Paraíba (UFPB). http://www.cca.ufpb.br/cca/contents/paginas/institucional/sobrecca/localizacao

Coletto-Silva, A. (2005). Implantação da meliponicultura e etnobiologia de abelhas sem ferrão em três comunidades indígenas no estado do Amazonas. Tese de Doutorado. Curso de Pós-Graduação em Entomologia, Manaus, Universidade Federal do Amazonas (UFAM). Tese de Doutorado-INPA/UFAM, 196 p.

Cortopassi-Laurino, M., Velthuis, H. H. W. \& Nogueira-Neto, P. (2007). Diversity of stingless bees from the Amazon forest in Xapuri (Acre), Brazil. Proceedings of Netherlands Entomological Society 1: 105-114.

Ferreira, R. C. C. (2015). Orientação magnética de nidificação da abelha cupira (Partamona cupira Smith), Monografia apresentada ao Curso Superior de Tecnologia em Agroecologia do Centro de Desenvolvimento Sustentável do Semiárido, da Universidade Federal de Campina Grande, 39 p.

Ferreira, R. P. (2009). Influência da Orientação, Sombreamento, e Substratos de Ninhos-Armadilha na Captura de Abelhas e Vespas Nidificantes em Cavidades Preexistentes. Dissertação. PPGCB. João Pessoa, 46 p.

Fidalgo, A. O. \& Kleinert, A. M. P. (2007). Foraging behavior of Melipona rufiventris Lepeletier (Apinae; Meliponini) in Ubatuba, SP, Brazil. Brazilian Journal of Biology 67(1), 133-140.

Fideles Filho, J., Beltrão, N. E. M., Rao, T. V. R. \& Nóbrega, J. Q. (2002). Efeitos da umidade do solo nas variáveis de crescimento e no rendimento do feijoeiro. In: XII Congresso Brasileiro de Meteorologia, Foz do Iguaçu - PR. Anais do XII Congresso Brasileiro de Meteorologia. São José dos Campos: Sociedade Brasileira de Meteorologia, 2002. 1, 1-6.

Frankel R. B., Blakemore R. P. \& Wolfe R. S. (1979). Magnetite in freshwater magnetic bacteria, Science 203(4387), 1355-1356. $10.1126 /$ science. 203.4387 .1355

Hilário, D. S., Ribeiro, M. F. \& Imperatriz-Fonseca, V. L. (2007). Wind effect on flight activity of Plebeia remota (Holmberg, 1903) (Apidae, Meliponini). Biota Neotropica, 7(3), 225-232.

Hilário, S. D.; Imperatriz-Fonseca, V. L. \& Kleinert, A. M. P. (2000). Flight activity and colony strength in the stingless bee Melipona bicolor bicolor (Apidae, Meliponinae) Revista Brasileira de Biologia 60(2), 299-306.

Hsu, C. Y.; Li C. W. (1994). Magnetoreception in Honeybees. Science, 265: 95-96.

Kerr, W. E. (1997). Meliponicultura: A importância da meliponicultura para o país. Biotecnologia, Ciência e Desenvolvimento, 1(3): 42-44.

Kerr, W. E., Carvalho, G. A., Nascimento, V. A., Bego, L. R., Alves, R. M. O., Martins, M. A. S. \& Souza, I. C. (1996). Abelha uruçu - biologia, manejo e conservação. Belo Horizonte: Fundação Acangaú, 144 p.

Kleinert-Giovannini, A. \& Imperatriz-Fonseca, V. L. (1986). Flight activity and responses to climatic conditions of two subspecies of Melipona marginata Lepeletier (Apidae, Meliponini). Journal of Apicultural Research, 25(1), 3-8.

Lacerda, D. C. O., Aquino, I. S., Borges, P. F. \& Barbosa, A. S. (2017). Influência dos pontos cardeais e colaterais na nidificação de abelhas nativas em colmeias octogonais. Gaia Scientia, 11(2), 203-217. http://dx.doi.org/10.21707/gs.v11.n02a014

Lima. R. (2015). Características Biológicas da Geoprópolis da Abelha Social sem Ferrão Uruçu (Melipona scutellaris Latreille, 1811) Proveniente da Baía do Iguape-BA. Dissertação de Mestrado. UFRB. Cruz das Almas-Bahia, 86 p.

Lindauer, M. \& Kerr, W. E. (1960). Communication between the workers of stingless bees. Bee World, 41(2), 29-41.

Lowenstam, H. A. (1962). Magnetite in denticle capping in recent chitons (Polyplacophora). Geological Society of America Bulletin, 73(4), 435-438.

Lowenstam H.A. (1981). Minerals formed by microorganisms. Science 211: 1126-1131.

Lucano, L. M. J. (2006). Caracterização de material magnético mineralizado em abelhas meliponini Schwarziana quadripunctata: magnetometria SQUID e Ressonância Ferromagnética. Tese de Doutorado. Centro Brasileiro de Pesquisas Físicas Rio de Janeiro.

Martins, C. F., Cortopassi-Laurino, M., Koedam, D.; Imperatriz-Fonseca, V. L. (2004). Tree species used for nidification by stingless bees in the Brazilian Caatinga (Seridó, PB, João Câmara, RN). Biota Neotropica, 4: 1-8.

Martins, C. F., Ferreira, R. P., Carneiro, L. T. (2012). Influence of the Orientation of Nest Entrance, Shading, and Substrate on Sampling Trap-Nesting Bees and Wasps. Neotropical Entomology 41(2), 105-111.

Mesquita, F. L. A., Alves, J. E. \& Freitas, B. M. (2002). Padrão diário de trabalho de operárias dos ninhos de moça branca (Frieseomelitta varia) ao longo do dia. Anais do V Encontro Sobre Abelhas, Ribeirão Preto, SP. p. 311.

Nogueira Neto, P. (1970). A criação de abelhas indígenas sem ferrão. Chácaras e quintais, 365 p. 
Research, Society and Development, v. 10, n. 7, e7310716350, 2021

(CC BY 4.0) | ISSN 2525-3409 | DOI: http://dx.doi.org/10.33448/rsd-v10i7.16350

Oliveira. F. L. (2012). Influence of climatic variations on the flight activity of the Jandaira bee Melipona subnitida Ducke (Meliponinae). Fortaleza, CE. Revista Ciência Agronômica, 43(3), 598-603.

Pirani, J. R. \& Cortopassi-Laurino, M. 1993. Flores e Abelhas em São Paulo. EDUSP/FAPESP, 192 p.

Roldão, Y. S. (2011). Termorregulação colonial e a influência da temperatura no desenvolvimento da cria em abelhas sem ferrão, Melipona scutellaris (Hymenoptera, Apidae, Meliponini). 90 p.

Silva, E. B. (2015). Biologia da conservação das abelhas sem ferrão na região de Bambuí-MG. VII Semana de Ciência e Tecnologia do IFMG campus Bambuí, VII Jornada Científica. https://www.bambui.ifmg.edu.br/jornada_cientifica/2014/resumos/Bio/bioabelhas.pdf

Silva, M. D. (2011). Why do the stingless bee Melipona scutellaris (Hymenoptera, Apidae) forage at high relative air humidity? Iheringia, Série Zoologia 101(12), 131-137. https://www.scielo.br/scielo.php?pid=S0073-47212011000100019\&script=sci_abstract

Silva, W. P. \& Paz, J. R. L. (2012). Abelhas sem ferrão: muito mais do que uma importância econômica. Natureza on line, 10(3): 146-152.

Srinivasan, M. V., Zhang, S. W. \& Bidwell, N. J. (1997). Visually mediated odometry in honeybees. Journal of Experimental Biology, 200: $2513-2522$.

Vaz, M. A. (2015). Influência dos Pontos Cardeais e Colaterais na Nidificação de Abelhas Nativas. Dissertação de Mestrado. PPGCAG, UFPB. Bananeiras$\mathrm{PB}, 36 \mathrm{p}$. 